\title{
Enhancing Nursing Education with Remote Access Laboratories
}

\author{
http://dx.doi.org/10.3991/ijoe.v8iS4.2279 \\ Les Bowtell, Clint Moloney, Alexander A. Kist, Victoria Parker, Andrew Maxwell, Natasha Reedy \\ University of Southern Queensland, Toowoomba, Australia
}

\begin{abstract}
Given the vast coverage area and dispersed population centres in which nursing professionals practice in Australia, Remote Access Laboratory (RAL) based learning activities would seem to be an ideal match. However while they are commonplace in engineering faculties; in other disciplines such activities are not widely used. This may well be due to the intricacies of these practicals not being as straightforward and readily reproducible as typical physics or science experiments.
\end{abstract}

In our chosen case, the safe practice of intravenous pump driver operations and related clinical reasoning skills are important components for the training of both registered nurses and nursing students. The aim of this research project is to develop and trial remote access technologies that enable nursing students to test their knowledge, skills, and clinical reasoning with intravenous infusion pump drivers. This has been possible by extending the concept of RAL from a physical and tangible experiment, to more conceptual experimentation in any form conducted remotely. In such a context clinical reasoning becomes possible.

This paper discusses a prototype system that has been built with collaborative input from the Faculty of Engineering and Surveying and the Department of Nursing and Midwifery. An initial evaluation with a group of nursing students has been completed to assess if such activities can assist with the training of student nurses. Previous work has identified the need to scaffold learning activities that rely on RAL technology; the key conclusion in this paper is that in the context of nursing this has to be taken a step further. RAL activities here require contextualisation to become an effective learning tool.

Index Terms-Remote Access Laboratory, Nursing, Clinical Reasoning, Human Machine Interface, IV pump.

\section{INTRODUCTION}

Learning activities in laboratories and experimentation play an important part in engineering education; nursing education on the other hand has largely focussed on simulation as a teaching strategy. Numerous projects in engineering have addressed the challenge of providing remote control to experiments though Remote Access Laboratories (RALs) $[1,2]$. This project is part of a broader initiative [3] to investigate whether RAL technology developed in Engineering can offer benefits to non-technical disciplines.

The implementation of RAL at the University of Southern Queensland has been established to provide access to computers within the network footprint of the university. This access is expanded to allow connection of both physical computers connected to experiments as well as virtualised experiments hosting software experiments. A second and more important distinguishing feature is that it is hosted as part of the core university data centre structure thus allowing it to be connected to learning management systems and identity services permitting a much tighter integration of the final resultant system [4].

This paper explores the use of RAL technology for learning activities in the Department of Nursing and Midwifery. Specifically it investigates an activity that allows rehearsal of professional practice skills, including anaesthetic delivery to patients via a remotely controlled infusion pumps.

In the field of nursing Ryan, Carton and Ali [5] have identified key issues regarding the paradigm shift from "on stage" to the virtual environment and recommend rethinking course designs; communications, partnerships and technology, in order to promote improvements in student learning environments.

Singh [6] recommends strategies promoting technology as innovation to support teaching practice and implementing technology on a needs basis. Singh identifies the issue of first generation e-learning as simply replicating the instructivist class room model, based heavily on printed texts and activities such as quizzes resulting in poor student performance. Singh instead advocates for blended delivery with more delivery mode choices offering students with social contact, engagement, interactivity, relevance, thus creating a meaningful learning environment, improving the effectiveness of their learning as evidence by the achievement of the learning outcomes.

RAL does exactly this, forming partnerships between both nursing and engineering academics, providing not only support, which is important for teachers in their ability to move from one paradigm to another, but it also produces the needed nexus between technology, pedagogy, content and knowledge [7] to promote student learning in the online learning environment.

Other advantages of RAL via the online learning environment include allowing students to study at their own pace, place and within a social community of practice [8]. It also provides a complimentary alternative learning environment outside the traditional lab based activities and provides all students whether internal or external potential to build knowledge by actively participating, rather than passively acquiring knowledge. This paper addresses the research question whether RAL activities can assists student nurses in developing clinical reasoning skills.

The remainder of the paper is organised as follows: Section II introduces the theoretical framework that forms the basis of this project, Section III outlines the learning activity and Section IV discusses the implementation of 
the activity. Section V contrasts expectations of student nurses and the learning activity. Section VI summarises lessons learned and future directions of this project.

\section{THEORETICAL FRAMEWORK}

\section{A. Enabling Learning Episodes with RAL}

Traditionally remote access laboratories have been defined as methods to provide off site access to remotely controlled hardware, such as robots [9] or laboratories [10]. In an attempt to make RAL technology and related learning activities accessible to non engineering faculties, Kist et al. [3] have expanded the traditional concept of RAL to conceptual experimentation in any form which is conducted remotely. Laboratory experiments can help to create "episodes:" "recollections of events in which the [learner] took part or at least observed," with the result that the experience is "linked to propositions [about facts, concepts, ideas] so that those propositions in turn are remembered and understood" [11, pp. 765-766].

Laboratory experiments and related learning experiences can therefore be investigated separately. Experiments include physical or conceptual spaces, were experience or events take place. The application of knowledge to develop skills and understanding form part of the experience. This broader definition of what constitutes a laboratory learning experience allows for greater flexibility in understanding the concept and application of remote access laboratories. A remote laboratory can be defined as an event that creates a learning experience via a remote interface to connect the students' understanding of relevant information, concepts or ideas (propositions).

Barak's [12] instructional principles on the effective design and used of ICT supported learning, also apply to ICT based laboratory work and include: "learning is contextual, learning is an active process, learning is a social process, reflective practice plays a central role in learning" [12, pp. 122-123]. These principles are derived from behavioural, cognitive and social learning theory; are not discipline specific and also apply to RAL learning activities.

An "environment, in which the pupil can construct knowledge and can reflect upon his interactions and thinking" is also important [13] and enforces that "learning implies the initiation of a thinking process" [p. 228]. Slangen \& Sloep [13] citing Jonassen [14] identify three general thinking tasks, i.e. basic, critical and creative thinking that are part of a complex thinking process. The authors also suggest that mind tools promote fluency in different ways of thinking as described in their model.

"Mind tools are computer applications that, when used by learners to represent what they know, necessarily engage them in critical thinking about the content they are studying ..." [15] and "they require students to think about what they know in different, meaningful ways" [p.24]. In the context of this nursing learning activity discussed in this paper, RAL can be classified as a mind tool. RAL has to deliver the intended learning outcomes as "the pedagogical effectiveness of any educational activity is judged by whether or not the intended learning outcomes are achieved" [16].

\section{B. Nursing and RAL}

The concept of remote simulation as a teaching strategy in nursing education, while not an entirely new concept, has experienced renewed interest in relation to its ability to improve clinical reasoning skills in student cohorts [1719]. The interest may relate to the advent of high fidelity patient simulators (HFPS) which can interact with the learner to represent changes in physiological parameters consistent with learner intervention. Renewed interest may also stem from the advances in communication technologies that can assist with teaching and learning experiences in the clinical setting [20].

One of the most powerful reasons for implementing a simulated learning program into nurse education has been communicated by Messmer who promotes these technologies as a solution to an escalating number of patient deaths as a direct result of iatrogenic causes [21]. Recent statistics assert that in Australia hospital death tolls are equivalent to two jumbo jet disasters annually, and that being a patient in an Australian hospital only places an already sick individual at greater risk [22].

Messmer outlines that in critical incidents which call for rapid decision making, patient outcomes are improved by targeting ways in which nurses can learn to deliver care under controlled and safe methods. It is suggested by Messmer that technologies of this nature are an appropriate means to better prepare a nursing students to perform more competently in stressful incidents [21].

In contrast with the real clinical setting, simulated clinical situations involve only a few safety concerns and allow instructors and preceptors to completely control the events even to the extent of allowing a fully synthesized, robotic simulation $[23,24]$. These virtual simulations then allow the student to gain competence by practicing a skill over and over without patient risk [23]. Simulations in this context are not synonymous with simulations in the context of engineering education, i.e, situations are simulated not systems.

Currently the literature on remote access technologies in nursing and healthcare is heavily weighted towards the use of remote robotic presence technologies as the dominant concept, with a lack of attention being devoted to alternative remote access teaching solutions for the nursing student $[25,26]$. Recent research outcomes by Sampsel et al. [27] are favourable and demonstrate a need to continue to probe this technology as a feasible teachinglearning tool that expands the resources available to enable [25].

The standout concept stemming from all of the literature on remote robotics in health care $[25,28,29]$ is that the technology has great potential in improving the clinical reasoning skills of health-care professionals allowing the clinician to practice a task and skill in a risk free environment, developing confidence and building competence $[17,30,31]$.

A further and vital rationale for remote access technologies is related to student, lecturer and industry feedback, and in response to contemporary research [6], government education and institutional policy to promote equity [32] for all students regardless of employment status [33], geography, and culture.

By relaying on RAL technology as remote conceptual experiment and mind tool allow the design of learning activities that achieve similar learning outcomes as have been highlighted in context of simulations in nursing education. 


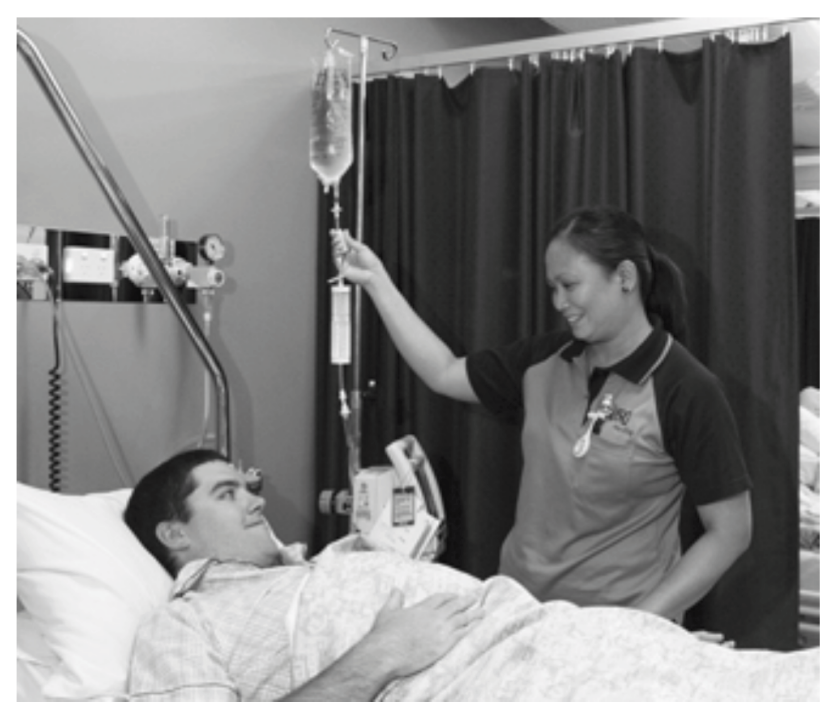

Figure 1. $1^{\text {st }}$ year nursing student tending to an IV infusion

\section{DeSIGN OF THE LEARNING ACTIVITY}

In a typical clinical situation (Figure 1), nurses are given an intravenous (IV) fluid order form as part of a patient's medication chart. The nurse must configure the IV infusion pump with correct rates and volumes of fluids to be administered including standard patient and infusion site checks. These checks would also include the correct tubing type for insertion into the pump and the correct drip-factor for the IV tubing. Following this process and commencement of IV therapy via the pump, nursing observations are then performed at regular intervals, typically on an hourly basis, to ensure the infusion is proceeding as planned, and the pump is functioning correctly according to calibrations. The designed activity incorporates these fundamental IV infusion pump configuration tasks and incorporates the key patient and infusion site checking aspects.

To compliment the RAL activity, pump practice scenarios would be introduced utilising an IV fluid order form and medication order chart for patient treatment. For example the Doctor may order Normal Saline 1000mls IV to be infused over an eight hour period. This may also be accompanied by a medication order for an IV antibiotic to be given over one half an hour intravenously. Students would typically be expected to complete an IV drug calculation determining the correct rate for infusion. Incorporated into the checking process would be an application of the six 'rights to medication safety', namely: 'right patient, right drug, right dose, right time, right route, and right to refuse'.

By implementing this project a decreased likelihood of patient error, stemming from the management of IV pumps by first year nursing students when on their first clinical placement, would be expected. The current teaching scenario in a nursing lab exposes nursing students to a total of two hours practice with IV pumps prior to clinical placement with real patients in the second year of the nursing program. Through this system it is anticipated there would be an increase in the access students have for practice in a laboratory environment from two hours a week to continuous real-time exposure to the IV pump in the lead up to this clinical placement. It is therefore expected that increased exposure to the RAL technology and associated clinical scenarios will serve to improve student clinical reasoning. Enhanced decision-making is then permitted in a controlled risk-free environment that will not directly cause patient harm.

\section{SYSTEM IMPLEMENTATION}

\section{A. Background}

Industrial supervisory control and data acquisition (SCADA) software such as Siemens WinCC [34] and Schnieder Electric's Citect [35] are used widely for industrial automation and control purposes. A feature of these is the ability to train operators with replay and simulated modes of operation to permit familiarisation with system controls under realistic circumstances. Operator's responses are able to be logged for later review and discussion. This allows a focus on embedding learning objectives within the experiment rather than development of training software from scratch. This style of training has been successfully used to train operators in key roles such as Energy network controllers [36], however implementation is relatively expensive, with typical single license costs of approximately \$2000USD.

\section{B. Application of RAL}

Students at USQ are able to leverage the desirable aspects of industrial SCADA software without spending thousands of dollars on license fees by using USQ's preexisting RAL system. The system is essentially an authenticated, mediated desktop control system allowing access to campus based PC's. 24/7 access worldwide means students can safely practice or refresh their knowledge just prior to placement in real-life patient situations. Access to the training system is on a one to one basis, where there is no risk of a dominant group member 'taking over'. Further by allowing individual what if scenario interaction the students can explore without risk of public humiliation if they enter incorrect infusion rates or set off an overvolume alarm.

\section{Implementation}

The clinical reasoning and Human Machine Interface (HMI) aspects of the experiment were documented by experienced nursing staff, and used to construct the clinical experiment process flowchart of Figure 3. Each aspect of interactivity represented in the flowchart is then converted into logical queries and functions for implementation in a programmable controller based SCADA system. Further functionality was added after initial trials to enhance the user interactivity of the system including ready access to scaffolding materials. The system has two distinct control elements: A programmable logic controller to execute logical based functions; and a SCADA software system to deal with HMI tasks.

\section{Programmable Controller}

The programmable controller allows multiple and complex logical pathways to achieve student interaction. This allows the student to explore 'what if?' scenarios and evaluate the relative merit of each approach. For example, the correct infusion rate and volume delivered to the patient can be arrived at in a number of ways and as long as the necessary patient checks are completed all are technically valid. The programmable controller makes logical assessments based on screen selection, validity of entered data and the current logical position as described by the flowchart of Figure 3. Additional alarm and warning noti- 
fications to the SCADA system HMI are also handled by the programmable controller. The experimental setup, including IV pump hardware and SCADA interface is shown in Figures 5 and 6.

The sequenced demonstration mode is achieved using so called step - transition logic within the programmable controller. Each logical condition must be met before transitioning to the next functional stage within the sequence. These logical sequences can be interrupted at any stage to allow the user the flexibility of referring back to scaffolding material. This material is made available via the SCADA software and therefore there is a required level of interactivity between the programmable controller and SCADA software. The SCADA package chosen for this system allows easy integration with the programmable controller at a number of levels. This allows seamless integration of the sequencing, audio and video aspects of the training system.

The SCADA system software allows interaction with the user based the keypad and menu buttons. The onscreen mimic of the infusion pump screen and keypads, as shown in Figure 4, is accomplished by associating object specific properties to graphical representations of each and every key, button and arrow. Special care is taken to ensure that navigation of screens and entry of data is functionally identical to that of the real infusion pump.

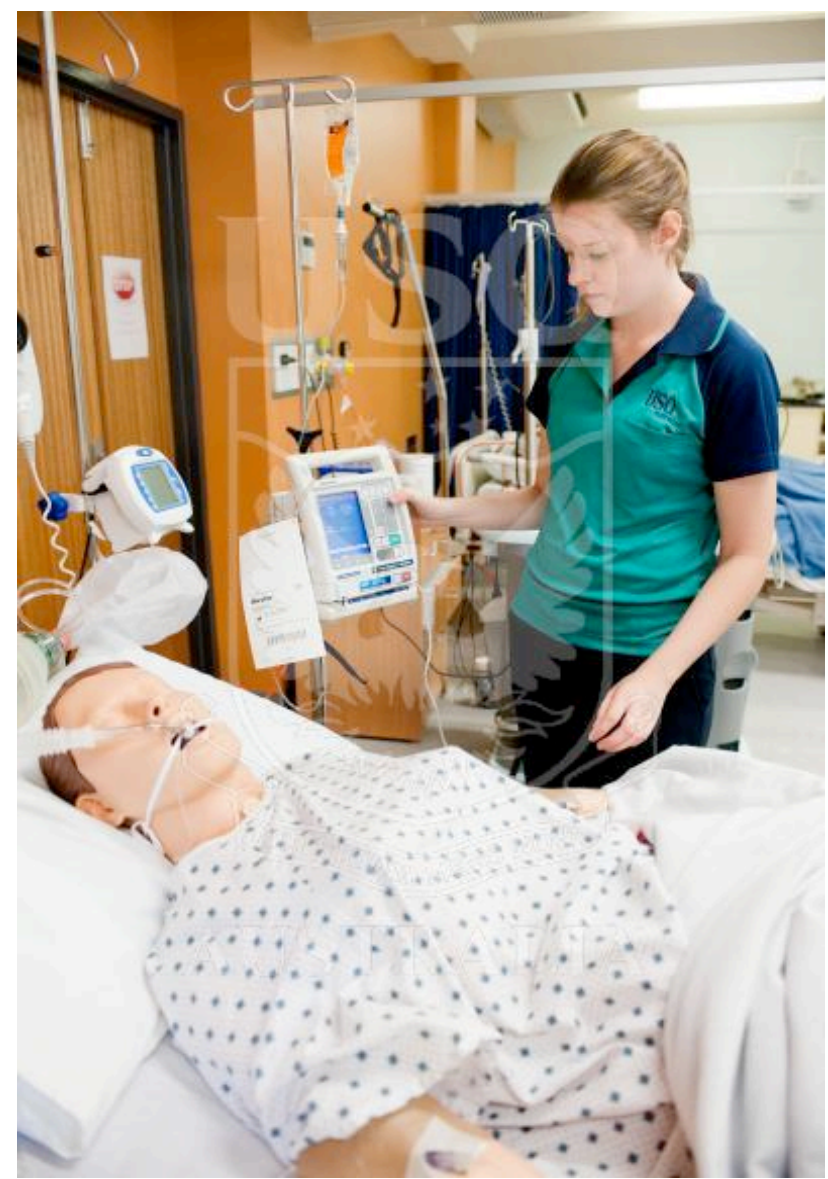

Figure 2. Simulated Ward Environment for IV Pump training

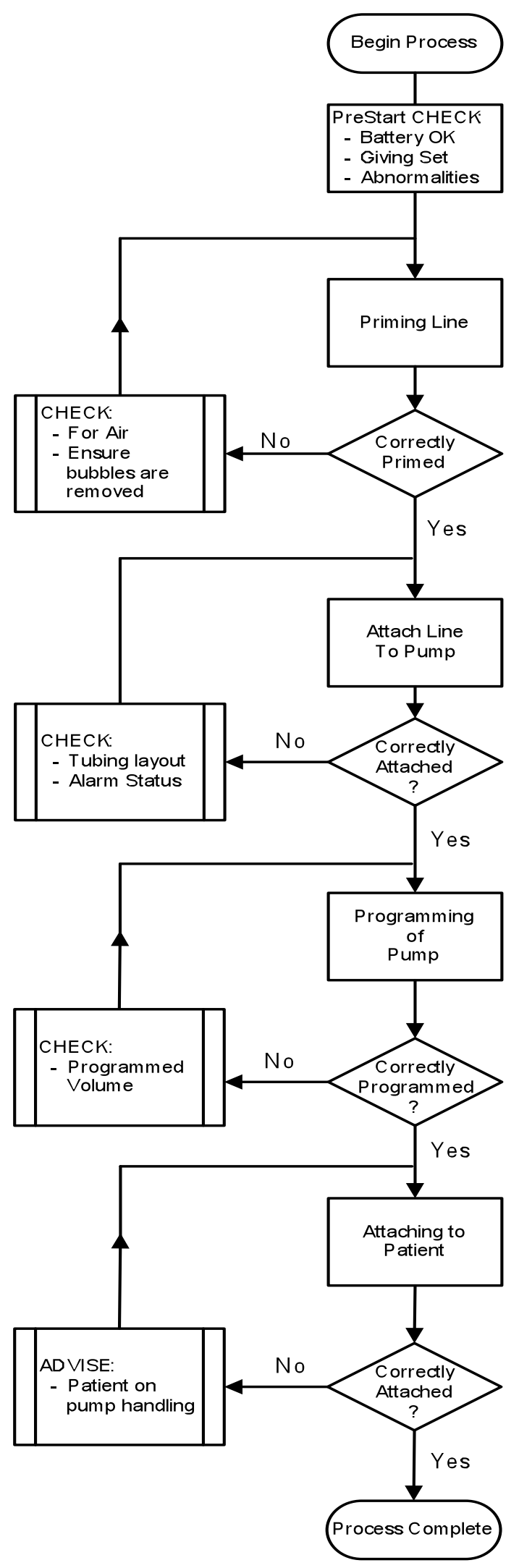

Figure 3. Clinical Experiment Process Flowchart 


\section{E. HMI software}

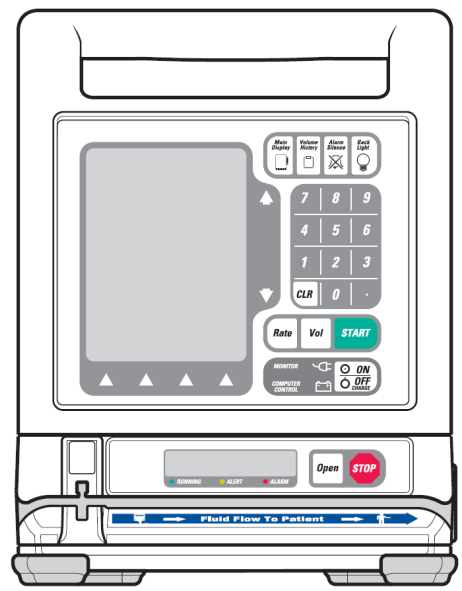

Figure 4. Typical Infusion pump HMI

In practice the main interactive element for the clinical nursing student is the infusion pump HMI. As medical instruments require effective use when the operator is using gloves the interface is not a touch-enabled device and is less intuitive than modern touch screen devices. In this case access to screen elements is via a membrane keypad with numeric entry keypad for entry of flow-rate and volumetric data. The SCADA system software allows interaction via the same style keypad, buttons and lights as the real system. Where possible the exact functionality of the IV infusion driver is mimicked by the SCADA system, including aspects such as sequence timing, visual and audible cues and warnings. The only exception to this approach was with the overall infusion timeframe which may take hours in practice.

\section{F. Operational modes}

Traditionally a 'user's manual' is the main resource used by trainees to gain a working knowledge of an IV infusion pump driver. Unlike modern software systems there is no on-line help or guided navigation for users. To overcome this shortcoming the RAL nursing infusion driver training system implements multiple modes or personalities to cater for different experience levels.

To introduce the user to the screen interface and infusion pump terminology the system employs a 'guided tour' approach. The user is visually and audibly prompted through the typical clinical steps of loading the line through to rate and volume selection and patient checks. This allows familiarisation with the interface and aims to mimic the role of a practical instructor. Standard prompts of each step indicate the required action and highlight the appropriate key to press. Figure 5 shows how these prompts are layered and can be overlaid the basic HMI.

Learning mode provides a less staged approach with selective hints to help guide the user through the basic entry of infusion rates and volume to be dispensed. This mode also queries the student at key operational stages with regard to performance of the required patient inspections and verbal advisement of specific patient rights. It is envisaged that students would typically need a few of these sessions to gain confidence in the IV pump driver usage. It may take longer however to fully understand the intricacies of Fluids orders and these are presented in case study format within the training system to further enhance the learning environment.

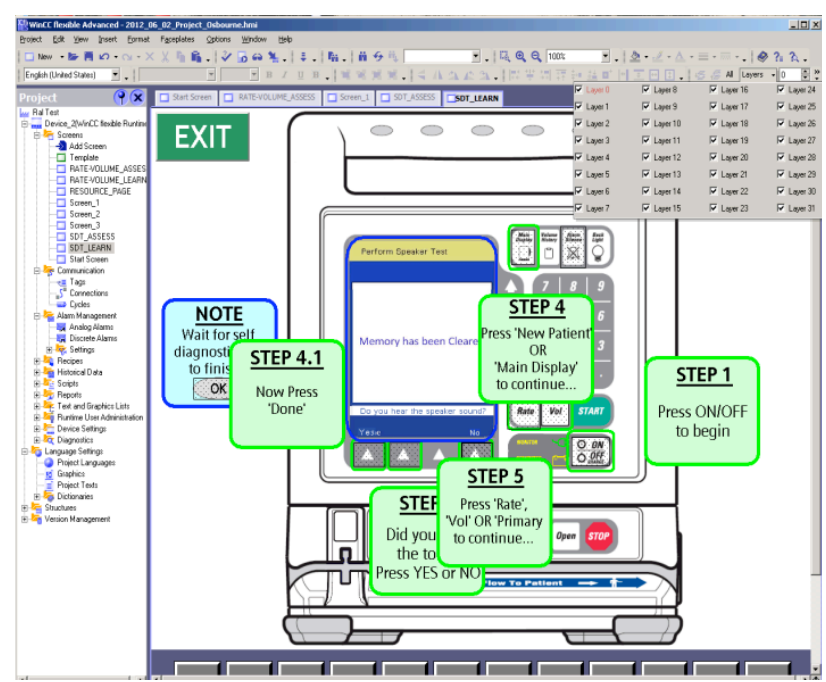

Figure 5. SCADA Graphical Design Interface showing Layers

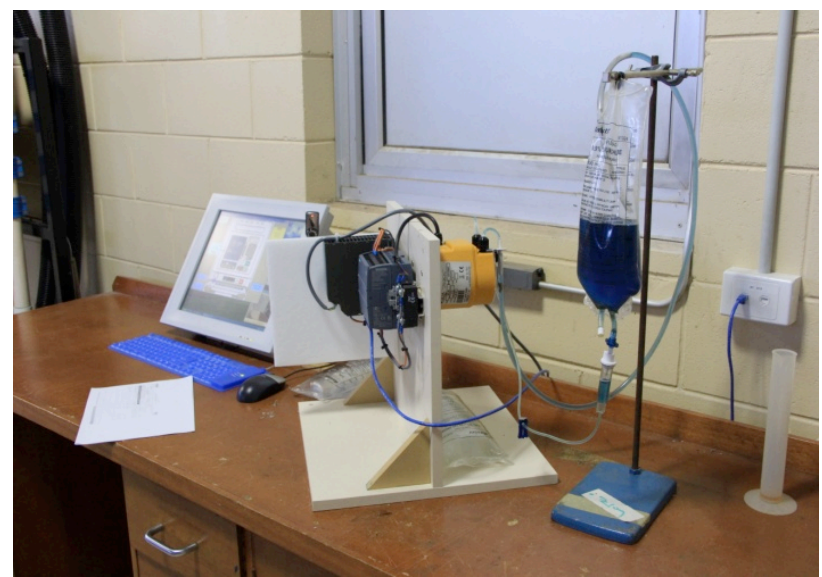

Figure 6. Experimental Layout

After students have familiarised themselves and are confident of their understanding an assessment mode allows a timed and recorded assessment to be made. Much like the actual Residential school assessment the student is given a case study to complete. These sessions are timed and any errors in calculations, process or clinical reasoning are recorded, during this assessment not additional help is available to the user. At the end of the session a summary screen indicating strengths and weaknesses is displayed so students can measure their progress. These additional enhancements will be assessed in the pilot study described in the following section.

\section{Methodology}

To get a better understanding of the way nursing students and teachers use the IV pump for learning and teaching data was collected by 2 hour observations of classes and a student focus group. Both were done by external consultants. The purpose of the focus group was to gain some insight into what students do to acquire the target skill and what their understanding of the skill is. Questions were used to prompt discussion around focal issues. The questions included:

- We saw one lab where people were being taught about setting up IV drips. Can you tell us about what that lab was like for you - what you were learning, was it hard, daunting, enjoyable etc? 
- What were the main things that you as nurses had to learn?

- How do you learn that?

- What did you struggle with most about this part of your course?

- You were allowed to take home drip bags to practice preparing the line. Did you practice it? How much?

- Where does this skill fit into nursing generally?

- Where does it fit into your course?

- Is there anything that you would like to see changed about the way you are taught this skill?

- What are you doing to improve your decision making processes in clinical settings?

- What is your prior experience if any of online services such as telehealth, online banking etc?

- What online tools do you use to support your learning - downloaded lectures, etc.

A key aim of this evaluation was to identify how well a RAL IV pump activity can supported skills acquisition.

\section{EVALUATION}

To evaluate potential learning affordances RAL IV pump activities could provide, a first year face-to-face class was observed whist students undertook their clinical practice activities. In class the lecturer introduced the procedure that is necessary to prime intravenous drip lines. This included demonstration of taking the cap off the fluid bag, piercing the bag, priming and clamping the line before inserting the line into the infusion pump. Students were told they would be given a bag to take home to practice the early steps on. The lecturer told the class that "putting the line into the pump can be temperamental" and that they would have to figure out what they needed to do to make it work.

Students were split into groups and provided with "case notes" for their simulated (plastic) patient so as to prepare the pump, calculate flow rates and familiarise themselves with the pump interface. From this, students had to establish understanding of the various alarms and fault conditions of the pump. Clearly, there were aspects of this exercise that could not be replicated remotely.

An important part of these learning activities were the case studies; together with the fake patient in the bed to enable students to practice discussion of medical information, processes for patient hand-over to other practitioners, and complete immersion in the bedside experience as well as the handling of the pump. In this practicum, students generally struggled with getting the pump to work and found the device alarms disconcerting. Teams operated with four members, resulting in delays to permit all members to practice manual skills, but provided a resource for working out responses. There is clearly a wealth of pedagogical content knowledge embedded in the design of such a class and the risk in developing a companion RAL is that the mechanics of the procedure will dominate at the expense of the other clinical skills.

Additionally, a focus group with twenty-six students was held to explore how such an IV pump RAL activity might be used. While one or two reported difficulties with alleged unreliable Internet connections at home, but most were quite familiar with computers, portable media players and smart phones. When asked what electronic aids they used, most often they listed online shopping, email, Facebook, video conference, learning management system (StudyDesk), course forums, recorded lectures, library sites and EndNote.

There was a great deal of enthusiasm from students for the notion of an electronic aid to learning the pump procedures, which they described as "frustrating", "daunting", "overwhelming", but also "quite interesting, actually, the pump checks in on you, what you're doing, that you have to put the line in a certain way". The RAL activity would, in students' estimation, surpass the problem of slow familiarisation times due to high student-toequipment ratios. They also cited the long class-to-class delays when practicing these skills, as an issue, with lower memory retention due to lack of concept reinforcement. While longer and more frequent face-to-face classes were mentioned as one way of improving this, students stated obvious utility for the use of a RAL to overcome these deficiencies.

The most obvious advantage was the flexibility of access time, allowing practice at their own pace, and in their own time with as many returns to the procedure as necessary to reinforce the acquired concepts. Students however did admit that although they had received saline bags practice some of the preparation procedures; 'none' had actually done so. Student discussions did show consensus that for review purposes, remote access was a useful learning process: "I think they should have it for just about all the classes. We were just...especially the handson...(sic)" Like the lecturer, students had preference where RAL would supplement the hands-on experience, and not replace it: "To have that hands-on, but like if you have the hands-on first, then you can go home and think 'Oh, I haven't quite got that'. And then you can review it on your computer at home. Well that would be good but if it totally replaced hands-on experience, I think it wouldn't work."

In discussing what student believed to be a benefit from RAL, they were adamant that it would need to be incorporated into a scenario (as their face-to-face classes had been) to establish a "reality". They also thought that a RAL would need to include problems which would increase in intensity as they solved earlier ones. For this to be possible they recognised that there would have to be feedback processes written into the RAL activity, in a more elaborate manner so as to permit student to establish "realistic answers". Another question posed was that of "loss of peer interaction" within a RAL activity environment.

In short, these students were alluding to the often claimed as the benefits of RAL; flexibility of access and the opportunity for repeated practice but were sceptical of the RALs' ability to deliver those other vaunted benefits: collaboration with peers and immediate feedback. These are characteristics of RALs which depend heavily of the pedagogical design of the activity and of the learningcourse using it.

A pilot study is also being undertaken to assess the effectiveness of the RAL based enhanced learning system. This study will be carried out in two stages, the first being Semester 2, 2012 with a follow up study in Semester 2, 2013. The pilot study will aim to directly compare a groups practical ability and clinical reasoning skills. This will be done in a residential school assessment after either 
having completed standard elements of study with or without the on-line component and a third group with both face to face and supplementary on-line training.

\section{CONCLUSION}

This paper has introduced a collaborative project between the Department of Nursing and Midwifery and the Faculty of Engineering to develop RAL activities for nursing education. It explores remote laboratory technology as a vehicle for rehearsing professional practice skills, i.e. anaesthetic delivery to patients. A prototype of a remotely accessible infusion pump has been designed and built.

On first impression this activity is similar to typical RAL activities in engineering; however, there is a major difference in anticipated learning outcomes. In engineering, learning outcomes usually relate to understanding the operation of technical equipment and related phenomena; here the key learning outcomes relate to the use of the equipment and related clinical reasoning skills. From a student and learning perspective, a scaffolded and integrated learning experience is important; and the attention to pedagogy for online learning tools is a necessity. The interviews with the nursing students suggest that this has to be expanded in the context of nursing. Contextualisation is crucial for RAL learning activities in nursing, but can be also important in other disciplines.

Further goals of the study include the development of software to support online student learning using principles of digital pedagogy and measure clinical reasoning. This study also has implications for Engineering Education. Insights gained about the use of RAL, as a pedagogical tool can be readily applied in the Engineering context. RAL has great potential and can be used in many more ways and for many more benefits than it is at present. As these benefits are largely offered remotely, RAL is particularly relevant in the context of distance education and can also play a role in improving opportunities for remote communities.

\section{ACKNOWLEDGMENT}

The authors would like to thank Daniel Osbourne for his contributions in the automation and SCADA areas; Lesley Jolly and Hannah Jolly, Strategic Partnerships, for their assistance with the evaluation and the Associate Deans (Learning and Teaching) at USQ for their support for this research project.

\section{VIII.REFERENCES}

[1] D. Lowe, et al., "LabShare: Towards a National Approach to Laboratory Sharing," in 20th Annual Conference of the Australasian Association for Engineering Education (AaeE), University of Adelaide, 2009.

[2] V. J. Harward, et al., "The iLab Shared Architecture: A Web Services Infrastructure to Build Communities of Internet Accessible Laboratories," Proceedings of the IEEE, vol. 96, pp. 931-950, 2008. http://dx.doi.org/10.1109/JPROC.2008.921607

[3] A. A. Kist, et al., "Expanding the Concept of Remote Access Laboratories " presented at the 119th ASEE Annual Conference and Exposition, San Antonio, Texas, 2012.

[4] A. A. Kist and P. Gibbings, "Inception and management of remote access laboratory projects," presented at the AaeE 2010: 21st Annual Conference of the Australasian Association for Engineering Education, Sydney, Australia, 2010.
[5] M. Ryan, et al., "Reflections on the role of faculty in distance learning and changing pedagogies," Nursing Education Perspectives, vol. 25, pp. 73-80, 2004.

[6] Singh, "Building effective blended learning programs," Educational Technology, vol. 43, pp. 51-54, 2003.

[7] P. Mishra and M. Koehler, "Technological pedagogical content knowledge: a framework for teacher knowledge," Teachers College Record, vol. 108, pp. 1017-1054, 2006. http://dx.doi.org/10.1111/j.1467-9620.2006.00684.x

[8] E. Wenger, Communities of Practice: Learning, Meaning, and Identity: Cambridge University Pres, 1998.

[9] G. V. Kondraske, et al., "Network-based infrastructure for distributed remote operations and robotics research," Robotics and Automation, IEEE Transactions on, vol. 9, pp. 702-704, 1993. http://dx.doi.org/10.1109/70.258062

[10] B. Aktan, et al., "Distance learning applied to control engineering laboratories," Education, IEEE Transactions on, vol. 39, pp. 320326, 1996. http://dx.doi.org/10.1109/13.538754

[11] R. T. White, "The link between the laboratory and learning," International Journal of Science Education, vol. 18, pp. 761 - 774, 1996. http://dx.doi.org/10.1080/0950069960180703

[12] M. Barak, "Instructional principles for fostering learning with ICT: teachers' perspectives as learners and instructors," Education and Information Technologies, vol. 11, pp. 121-135, 2006. http://dx.doi.org/10.1007/s11134-006-7362-9

[13] L. A. M. P. Slangen and P. B. Sloep, "Mind tools contributing to an ICT-rich learning environment for technology education in primary schools," International Journal of Continuing Engineering Education and Life Long Learning, vol. 15, pp. 225239, 2005. http://dx.doi.org/10.1504/IJCEELL.2005.007712

[14] D. H. Jonassen, Computers as mindtools for schools: engaging critical thinking: Merrill, 2000.

[15] D. Jonassen, et al., "Computers as mindtools for engaging learners in critical thinking," TechTrends, vol. 43, pp. 24-32, 1998. http://dx.doi.org/10.1007/BF02818172

[16] F. Arango, et al., "A Scenario for Collaborative Learning in Virtual Engineering Laboratories," in 37th ASEE/ISEE Frontiers in Education Conference, Milwaukee, WI, 2007, pp. F3G-7 F3G-12.

[17] T. Levett-Jones, et al, "'The 'five rights' of clinical reasoning: An educational model to enhance nursing students' ability to identify and manage clinically 'at risk' patients'," Nurse Education Today, vol. 30, pp. 515-520, 2010. http://dx.doi.org/10.1016/j.nedt. 2009.10.020

[18] N. Harder, "Use of Simulation in Teaching and Learning in Health Sciences: A Systematic Review," Journal of Nursing Education, vol. 49, pp. 23-28, 2010. http://dx.doi.org/10.3928/ 01484834-20090828-08

[19] T. Pike and V. O'Donell, "The impact of clinical simulation on learner self-efficacy in pre-registration nursing education," Nurse Education Today, 2010. http://dx.doi.org/10.1016/j.nedt.2009. $\underline{09.013}$

[20] C. Moloney and L. M. Beccaria, "Perceived facilitators and inhibitors for the use of personal digital assistants (PDAs) by nurses: a systematic review," JBI Library of Systematic Reviews, vol. 7, pp. 1430-1491, 2009.

[21] P. Messmer, "Enhancing Nurse-Physician Collaboration Using Pediatric Simulation," Journal of Continuing Education in Nursing, vol. 39, 2008.

[22] D. M. Watson, "Can Teaching interprofessional communication and teamwork through simulation create efficient patient care and better use of resources?'," 2010.

[23] Rauen, "Simulation as a Teaching Strategy for Nursing Education and Orientation in Cardiac Surgery " Critical Care Nurse, vol. 24, pp. 46-51, 2004.

[24] E. Bandman, Bandman, B, "Critical Thinking in Nursing," 1995.

[25] D. Sampsel, et al., "Robots as Faculty: Student and Faculty Perceptions," Clinical Simulation in Nursing, vol. In Press, Corrected Proof, 2010.

[26] Medical_News_Today, "Robot Joins Nursing Institute Of West Central Ōhio To Address Faculty Shortage," 2007. 
[27] D. Sampsel, et al., "Robots as Faculty: Student and Faculty Perceptions," vol. 7, pp. e209-e218, 2011.

[28] ABC_news, "Remote-control robot performs heart surgery," 2011.

[29] S. S. Rothenberg, et al., "Initial Experience with Surgical Telementoring in Pediatric Laparoscopic Surgery Using Remote Presence Technology," Journal of Laparoendoscopic \& Advanced Surgical Techniques, vol. 19, pp. s219-s222, 2009. http://dx.doi.org/10.1089/lap.2008.0133.supp

[30] C. G. Ferrario, "Experienced and Less-Experienced Nurses' Diagnostic Reasoning: Implications for Fostering Students' Critical Thinking," International Journal of Nursing Terminologies \& Classifications, vol. 14, p. 41, 2003. http://dx.doi.org/10.1111/j.1744-618X.2003.tb00059.x

[31] Z. Munn, "Eye irrigation for patients with ocular chemical burns: a systematic review; Effectiveness of nurse-led preoperative assessment services for elective surgery: a systematic review; The effectiveness of using human patient simulation manikins in the teaching of clinical reasoning skills to undergraduate nursing students: a systematic review; The effectiveness of educational strategies in improving parental/caregiver management of fever in their child: a systematic review," Journal of Advanced Nursing, vol. 66, pp. 2391-2397, 2010.

[32] H. Pillay, "A new paradigm for ethical and sustainable indigenous knowledge policy," Ch 17 in Hearn, G., \& Rooney, D. (eds).Knowledge policy: challenges for the 21st century. USA: Edward Elgar. , 2008.

[33] D. Oblinger, "Boomers and gen-X's, Millenialls, Understanding the new students," Educause, pp. 37-47, 2003.

[34] "Siemens S7-1200 Programmable controller, System Manual," 04/2009.

[35] T. Sun, et al., "Application of WinCC in Carplant Monitoring System," presented at the International Symposium on Computer Science and Society (ISCCS), 2011. http://dx.doi.org/10.1109/ ISCCS.2011.63

[36] R. Gillet, "Pre-Dispatch Process Description," AEMO Market Operations01/07/2010.

\section{AUTHORS}

Les Bowtell is with the Faculty of Engineering and Surveying at the University of Southern Queensland, Toowoomba, Queensland 4350, Australia (e-mail: Les.Bowtell@usq.edu.au).

Clint Moloney is with the Department of Nursing and Midwifery, Faculty of Science at the University of Southern Queensland, Toowoomba, Queensland 4350, Australia (e-mail: Clint.Moloney@usq.edu.au).

A.A. Kist is with the Faculty of Engineering and Surveying at the the University of Southern Queensland, Toowoomba, Queensland 4350, Australia (e-mail: kist@ ieee.org).

Victoria Parker is with the Department of Nursing and Midwifery, Faculty of Science at the University of Southern Queensland, Toowoomba, Queensland 4350, Australia (e-mail: Victoria.Parker@usq.edu.au).

A. Maxwell is with the Faculty of Engineering and Surveying at the University of Southern Queensland, Toowoomba, Queensland 4350, Australia (e-mail: andrew.maxwell@usq.edu.au).

Natasha Reedy is with the Department of Nursing and Midwifery, Faculty of Science at the University of Southern Queensland, Toowoomba, Queensland 4350, Australia (e-mail: Natasha.Reedy@usq.edu.au).

This work was supported by a USQ Learning and Teaching Performance Fund grant. It is an extended and modified version of a paper presented at the International Conference on Remote Engineering \& Virtual Instrumentation (REV2012), held at University of Deusto, Bilbao, Spain, July 4-6, 2012. Received 15 September 2012. Published as resubmitted by the authors 28 November 2012 . 